\title{
News from Rhinology Journal
}

Rhinology Journal is thriving. We have a new impact factor of 3.68. We are growing every year and hopefully next year we will be over 4 .

Another big change is the expansion of the editorial team with four associate editors: Claire Hopkins, Basile Landis, Sietze Reitsma and Ahmad Sedaghat. I am extremely happy and grateful that these 4 associate editors will share the work with me of handling the many papers send to us.

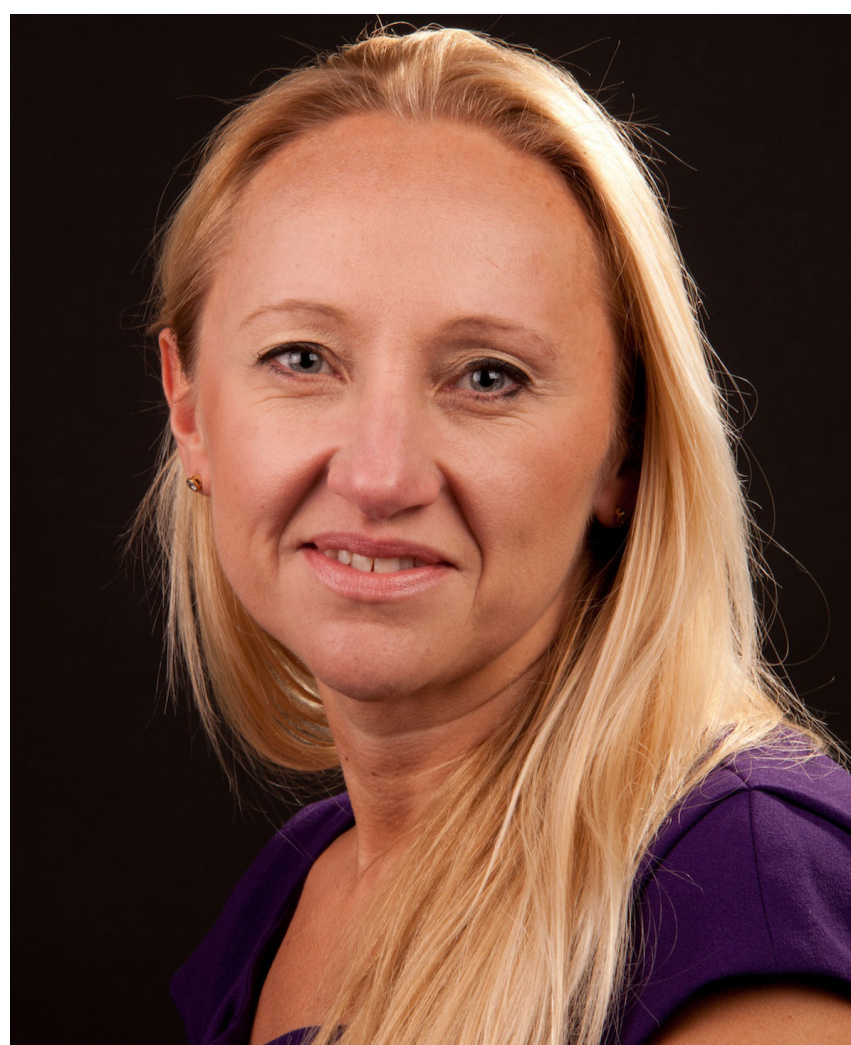

Claire Hopkins is an ENT surgeon at Guy's Hospital, a large academic centre, in London and a Professor of Rhinology at King's College, London. She runs an active research programme centred on evaluating the effectiveness of treatments for sinonasal conditions, focusing on patient rated outcomes in randomised trials and systematic reviews and has published extensively in this field. "I'm delighted to be appointed as an associate editor; I've been submitting manuscripts to the journals as well as reviewing for many years, and it's a great honour to join the editorial board. The journal is going from strength to strength and is now one of the leading journals within our specialty - I hope I can contribute to its ongoing success".
In 2020 we received over 650 papers that are reviewed by a team of over 80 reviewers. The coming of these new highly experienced professionals will further improve the high quality constructive reviews and fast response time.

Rhinology is ready for your contributions and these new developments will ensure that we can serve you in the best possible way.

Wytske J. Fokkens, Editor-in Chief

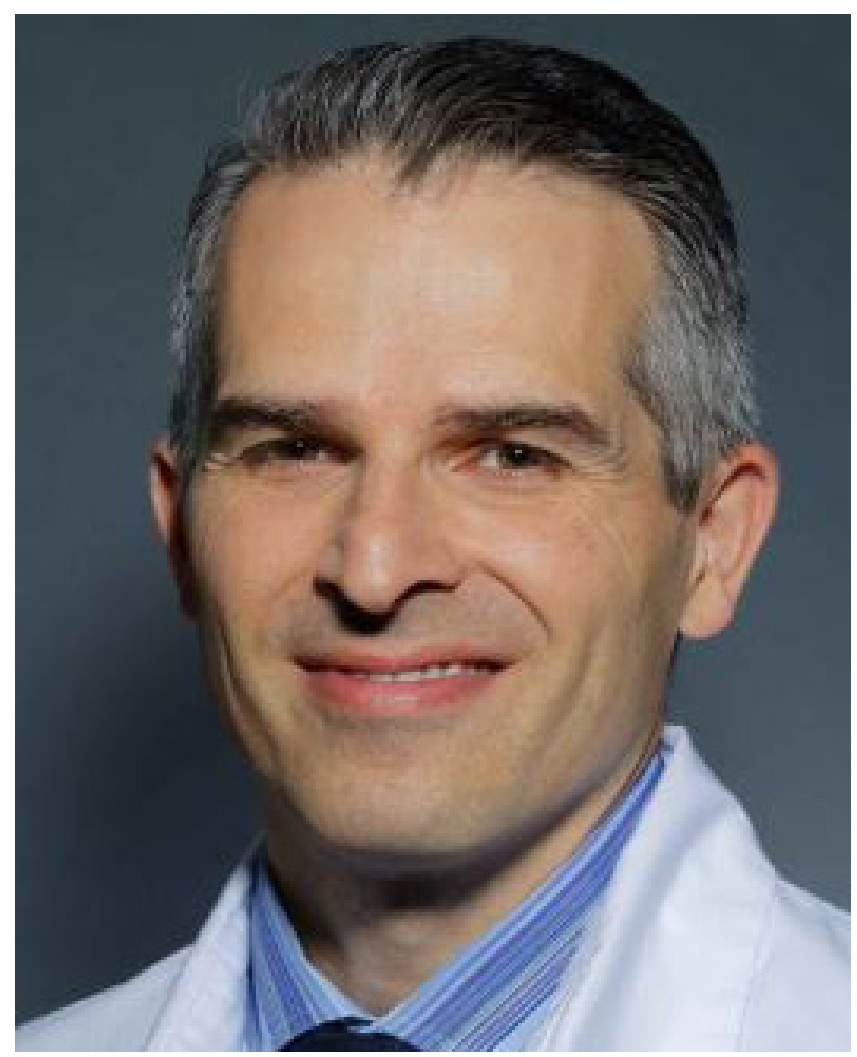

Basile N. Landis works as professor and head of the Rhinology Unit at the Geneva University Hospital for almost a decade and finds the ongoing evolution in the field of clinical, experimental and research rhinology extremely interesting. "I am passionate to contribute to these changes. My focus and background is on smell and taste, a field that perfectly reflects the nature of rhinology as a translational, medical and surgical discipline that is always in collaboration and at the border to other medical specialties. Rhinological affections concern almost all ages and most people once in their lifetime. Despite that, rhinology has historically been underestimated for many years. Rhinology as one of the first specialty journals focusing on exclusively nasal matters has substantially helped to change this perception within ENT. Besides being a big honor, I hope as AE to help perpetuate and improve the quality, visibility and impact of the work our colleagues all around the globe do. 


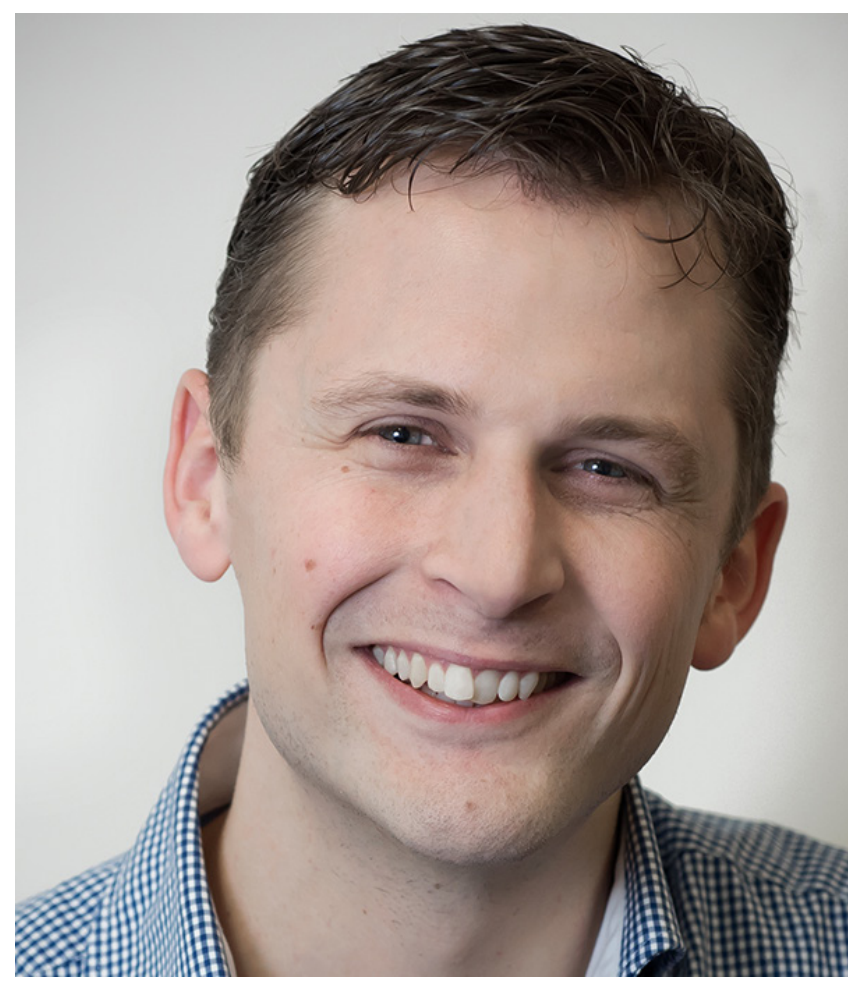

Sietze Reitsma is Rhinologist at the Amsterdam University Medical Centres, location AMC.

" In my work as a rhinologist at the Amsterdam University Medical Centre, rhinological research is a key element of my day-to-day life. For it is research, both basic and clinical, that paves the way for new and optimized treatment for our patients. It deepens our understanding, and shows us subjects and areas where we still lack insight. As a journal, Rhinology plays a pivotal role in this process by enabling researchers from all over the world to connect and present their data, ideas and concepts. As an associate editor to Rhinology, I will contribute to this highquality journal aiming to increase its global impact. Such a mission can only be accomplished together with our great editorial board under the skillful guidance of our Editor in Chief".

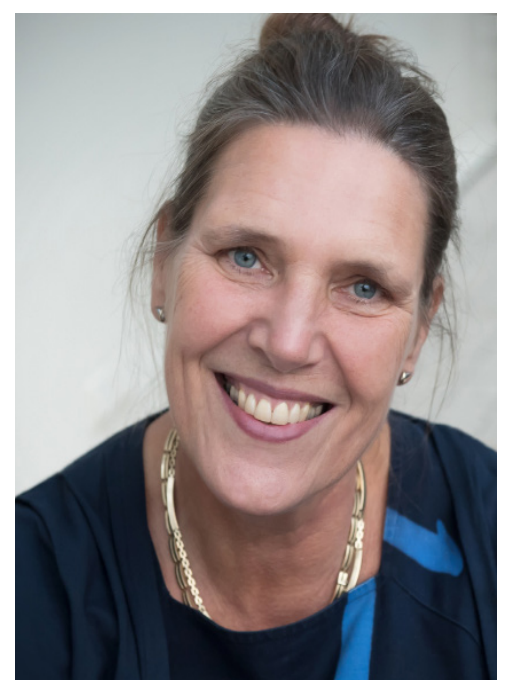

Wytske J. Fokkens, Editor-in Chief

Amsterdam, the Netherlands

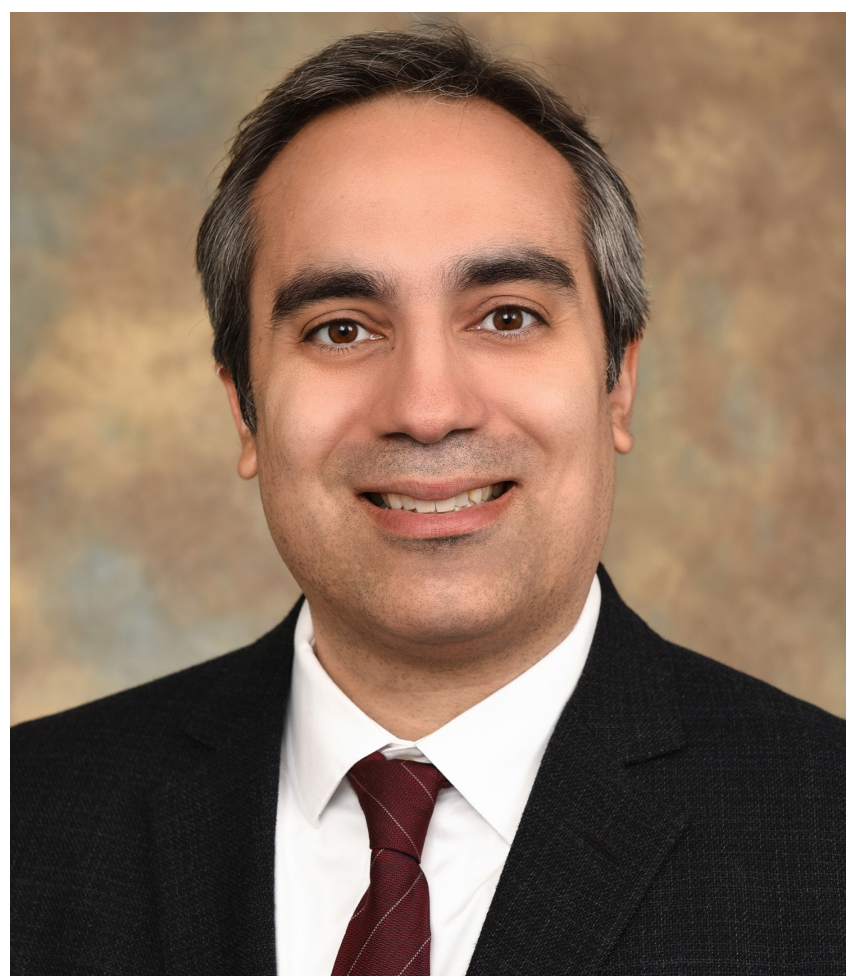

Ahmad R. Sedaghat is the Director of the Division of Rhinology, Allergy and Anterior Skull Base, Director of Clinical Research and Associate Professor in the Department of Otolaryngology - Head and Neck Surgery at the University of Cincinnati College of Medicine. "I am a rhinologist with an active research program focused on chronic rhinosinusitis that spans the realm of clinical research and translational immunology. My vision for Rhinology journal is to continue as an international leader for disseminating the highest quality scientific evidence informing our field's knowledge of rhinologic conditions and their treatments. I also look forward to continuing a superior author experience - from an expeditious peer-review process to the uniform provision of high quality, constructive, and transparent reviews for our authors. I am grateful and honored to be part of this amazing editorial team, and look forward to working with them on the future of Rhinology". 